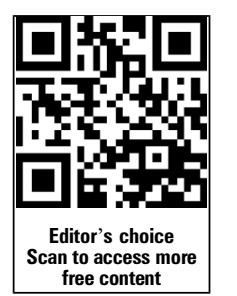

${ }^{1}$ Faculty of Public Health, Mahidol University, Bangkok, Thailand

${ }^{2}$ Center of Excellence on Environmental Health and Toxicology, Bangkok, Thailand ${ }^{3}$ Tobacco Control Research and Knowledge Management Center, Bangkok, Thailand

${ }^{4}$ Thailand Health Promotion Institute, Bangkok, Thailand

\section{Correspondence to} Naowarut Charoenca, Faculty of Public Health, Mahidol University, 420/1 Rajvithi Rd, Bangkok, Thailand; nao.naowarut@yahoo.com

Received 23 Auqust 2013 Accepted 26 February 2014 Published Online First 17 March 2014

\title{
Assessment of secondhand smoke in international airports in Thailand, 2013
}

\author{
Nipapun Kungskulniti, 1,2 Naowarut Charoenca, 1,2 Jintana Peesing, ${ }^{3}$ \\ Songwut Trangwatana, ${ }^{3}$ Stephen Hamann, ${ }^{3}$ Siriwan Pitayarangsarit, ${ }^{3}$ \\ Hatai Chitanondh ${ }^{4}$
}

\begin{abstract}
Objective To assess secondhand smoke (SHS) exposure in Thai international airports using a fine particulate indicator, particulate matter $\leq 2.5 \mu \mathrm{m}\left(\mathrm{PM}_{2.5}\right)$, and to compare with 2012 exposure findings in international airports in the USA.

Methods Smoking rooms in the four largest international airports that serve the most travellers and with the most operating designated smoking rooms (DSRs) were monitored using $\mathrm{PM}_{2.5}$ monitoring equipment following an approved research protocol for assessing fine particle pollution from tobacco smoke. Monitoring was conducted inside and just outside DSRs and throughout the airport terminals in all four airports. Altogether 104 samples were taken to assess SHS exposure in four airports. Simultaneous samples were taken multiple times in a total of 11 DSRs available for sampling in the research period.
\end{abstract}

Results Levels of $\mathrm{PM}_{2.5}$ in DSRs were extremely high in all four airports and were more dangerous inside DSRs than in the US airports (overall mean $=532.5$ vs $188.7 \mu \mathrm{g} / \mathrm{m}^{3}$ ), higher outside DSRs than in the US airports (overall mean $=50.1$ vs $43.7 \mu \mathrm{g} / \mathrm{m}^{3}$ ), and at comparable levels with the US airports in the terminals away from DSRs (overall mean $=13.8 \mathrm{vs} 11.5 \mu \mathrm{g} / \mathrm{m}^{3}$. Findings show that travellers and employees in or near DSRs in the airports assessed in Thailand are being exposed to even higher levels of SHS than in US airports that still have DSRs.

Conclusions Extremely high levels of SHS in and adjacent to DSR show that these rooms are not providing safe air quality for employees and travellers. These high levels of exposure are above those levels reported in US airports and show the need for remedial action to ensure safe air quality in international airports in Thailand.

\section{INTRODUCTION}

In 1992, national legislation, the Thai NonSmokers Health Protection Act, specified a number of measures to protect non-smokers from secondhand smoke (SHS). ${ }^{1}$ Some measures like allowing designated smoking rooms (DSRs) were inadequate. Incremental changes strengthening the law followed through research evidence of SHS dangers, though slowed by actions taken by the tobacco industry to divert the overall smoke-free movement. ${ }^{2}{ }^{3}$ The tobacco industry was particularly clever in using the hospitality industry as a front group to make economic and 'ventilation' arguments, though these arguments were not credible based on economic and air quality studies. ${ }^{4}$ Despite industry efforts, air quality studies in Thailand resulted in evidence making Thailand nearly $100 \%$ smoke free $^{5-7}$

\section{Smoking in airports}

Past studies have focused on showing that DSRs do not provide safe air quality for airport employees or customers. ${ }^{8-10}$ High-income countries like Australia have banned smoking in airports simultaneously with bans on smoking during air travel. ${ }^{11}$ In contrast, smoking in Thai international airports is still allowed. A recent US study of large hub airports showed that several major airports in the USA still had unacceptable SHS exposure from smoking restaurants, rooms or lounges, even though over 600 US airports of all sizes are smoke free. ${ }^{12} 13$ This rather surprising SHS exposure in US large-hub airports precipitated this study of smoking in Thailand's airports. Thailand's latest regulation to protect the health of non-smokers prohibits smoking in domestic airports, but allows DSRs in international airports. ${ }^{14}$ Recent evidence showing that most international tourists visiting Thailand prefer smoke-free areas also makes it timely to investigate the actual level of SHS exposure in DSRs in Thailand. ${ }^{15}$

\section{METHODS}

In March-April 2013, the four largest international airports in Thailand were selected for study because they had the most operating DSRs. They served an estimated 64 million travellers in 2011. Locations were monitored during at least two periods of morning, afternoon or evening in each airport, including inside DSRs (one in airports $\mathrm{A}$ and $\mathrm{B}$; three in airport $\mathrm{C}$; and six in airport $\mathrm{D}$ ), areas adjacent to the smoking rooms and non-smoking areas. Areas adjacent to smoking rooms were areas $1 \mathrm{~m}$ $(3.3 \mathrm{ft})$ from the door of the smoking room at breathing zone height as used in research in the US study. ${ }^{12}$ These locations were monitored to assess the leakage of SHS to the surrounding areas. Results from non-smoking areas of each airport were compared with results from DSRs and areas adjacent to DSRs. Statistical analysis for the log-transformed data of the three airport locations monitored used analysis of variance.

Particulate matter $\leq 2.5 \mu \mathrm{m}\left(\mathrm{PM}_{2.5}\right)$ was used as an indicator of SHS exposure according to best practice and an expert-developed protocol for such monitoring. ${ }^{16}{ }^{17}$ The real-time TSI Sidepak AM510 Personal Aerosol Monitor was used, $30 \mathrm{~min}$ for each measurement, to determine levels of $\mathrm{PM}_{2.5}$ in $\mu \mathrm{g} / \mathrm{m}^{3}$. Sampling of $\mathrm{PM}_{2.5}$ was done
To cite: Kungskulniti

et al. Tob Control

2015;24:532-535. 
simultaneously inside and adjacent to DSRs by two researchers. The results of each sample taken at $1 \mathrm{~min}$ intervals were downloaded onto a computer, and analysed and compared by location. A calibration factor of 0.32 and a flow rate of 1.7 $\mathrm{L} / \mathrm{min}$. was used for the data from the three instruments used in measuring $\mathrm{PM}_{2.5}$ levels.

\section{RESULTS}

Data from 104 samples overall were analysed for mean levels of $\mathrm{PM}_{2.5}$ from study sites in the four international airports as shown in table 1 . The overall mean $\mathrm{PM}_{2.5}$ levels in the smoking rooms were $532.5 \mu \mathrm{g} / \mathrm{m}^{3}, 50.1 \mu \mathrm{g} / \mathrm{m}^{3}$ in areas adjacent to the smoking rooms, and $13.8 \mu \mathrm{g} / \mathrm{m}^{3}$ in non-smoking areas. The levels of $\mathrm{PM}_{2.5}$ were significantly different for all three areas studied $(p<0.05)$. The high levels of detected $\mathrm{PM}_{2.5}$ for the areas adjacent to the smoking rooms indicate leakage of SHS from inside the smoking rooms. The Spearman rank correlation coefficient ( $\mathrm{rsp}=0.791,95 \%$ CI 0.550 to $0.916, \mathrm{p}<0.01$ ) indicates a considerable correlation between the two areas. Figure 1 illustrates how DSR levels had corresponding levels outside DSRs. Non-smoking areas had much lower $\mathrm{PM}_{2.5}$ exposure levels than the areas adjacent to the smoking rooms (13.8 vs $50.1 \mu \mathrm{g} / \mathrm{m}^{3}$ ). Levels just outside smoking rooms were about four times the levels in smoke-free areas.

The same pattern of $\mathrm{PM}_{2.5}$ levels was observed in all four international airports with the highest levels measured in the DSRs. The levels detected in each of the three locations in every airport were significantly different. Further, the mean level of $\mathrm{PM}_{2.5}$ in the DSR of airport $\mathrm{B}$ was alarmingly high, $1793.9 \mu \mathrm{g} / \mathrm{m}^{3}$, with the area adjacent to the DSR at $155.9 \mu \mathrm{g} / \mathrm{m}^{3}$. It was noticed that this particular DSR opened onto a small convenience store, already in violation of Thai smoke-free regulations as a licensed public shop. Therefore, smokers inside the DSR and hundreds of travellers and airport employees who used this shop were affected every day.

The overall mean $\mathrm{PM}_{2.5}$ levels in DSRs and areas adjacent to DSRs were higher in Thai international airports than levels found in the USA $\left(532.5\right.$ vs $188.7 \mu \mathrm{g} / \mathrm{m}^{3}$ and 50.1 vs $\left.43.7 \mu \mathrm{g} / \mathrm{m}^{3}\right)$.

\section{DISCUSSION}

SHS exposure in DSRs and adjacent to DSRs in Thailand were much higher than levels found in the USA. For example, in the US Environmental Protection Agency air quality index used to warn the public of air pollution dangers, levels over $250 \mu \mathrm{g} / \mathrm{m}^{3}$ are hazardous and levels over $40 \mu \mathrm{g} / \mathrm{m}^{3}$ are considered unhealthy for sensitive groups. SHS has been recognised as the most common source of indoor air pollution, yet it is surprising that exposure levels found in small DSRs in Thailand have reached more than 20 times the $24 \mathrm{~h}$, short time indoor air pollutant level of $25 \mu \mathrm{g} / \mathrm{m}^{3}$ in WHO guidelines. ${ }^{18}$

Recent research confirms the extreme dangers of SHS exposure, especially regarding vulnerable populations like babies and children, and the adverse short-term effects of SHS on cardiovascular health. ${ }^{19}$ It is now clear that smoke-free places can go a long way to eliminate the smoke-related threats to every biological system of the body. ${ }^{20}$

Though smoke-free policy is desirable in international airports based on the serious health effects known to result from SHS exposure, no action to ban smoking in Thai international airports has yet been taken.

Past document research of tobacco industry consultants and commercial allies shows they have spent considerable time and money to promote 'accommodation' or 'ventilation' solutions to address SHS exposure indoors. ${ }^{21}$ Past research shows that these measures do not work. ${ }^{8}$ Though Thailand has aimed for a comprehensive ban, it is sometimes problematic when one takes

Table 1 Levels of $\mathrm{PM}_{2.5}$ in smoking rooms, adjacent to smoking rooms and non-smoking areas of the four airports

\begin{tabular}{|c|c|c|c|}
\hline Location & Mean $\mathrm{PM}_{2.5}\left(\mu \mathrm{g} / \mathrm{m}^{3}\right)$ & $95 \% \mathrm{Cl}$ & p Value* \\
\hline \multicolumn{4}{|l|}{ Airport A (18 measurements) } \\
\hline Smoking rooms & 348.5 & 199.2 to 497.8 & \multirow[t]{3}{*}{0.000} \\
\hline Adjacent to smoking rooms & 17.2 & 12.4 to 22.0 & \\
\hline Non-smoking areas & 9.6 & 7.7 to 11.6 & \\
\hline \multicolumn{4}{|l|}{ Airport B (19 measurements) } \\
\hline Smoking rooms & 1793.9 & 1476.2 to 2111.4 & \multirow[t]{3}{*}{0.000} \\
\hline Adjacent to smoking rooms & 155.9 & 90.3 to 221.7 & \\
\hline Non-smoking areas & 13.2 & 9.7 to 16.8 & \\
\hline \multicolumn{4}{|l|}{ Airport C (24 measurements) } \\
\hline Smoking rooms & 799.4 & 508.9 to 1090.0 & \multirow[t]{3}{*}{0.000} \\
\hline Adjacent to smoking rooms & 33.2 & 28.6 to 37.9 & \\
\hline Non-smoking areas & 23.4 & 18.7 to 28.1 & \\
\hline \multicolumn{4}{|l|}{ Airport D (43 measurements) } \\
\hline Smoking rooms & 151.9 & 106.4 to 197.4 & \multirow[t]{3}{*}{0.000} \\
\hline Adjacent to smoking rooms & 12.0 & 11.1 to 12.8 & \\
\hline Non-smoking areas & 8.9 & 7.1 to 10.8 & \\
\hline \multicolumn{4}{|l|}{ Overall (104 measurements) } \\
\hline Overall mean for smoking rooms & 532.5 & 354.0 to 710.9 & \multirow[t]{3}{*}{0.000} \\
\hline Overall mean for adjacent to smoking rooms & 50.1 & 25.6 to 74.6 & \\
\hline Overall mean for non-smoking areas & 13.8 & 11.2 to 16.5 & \\
\hline
\end{tabular}




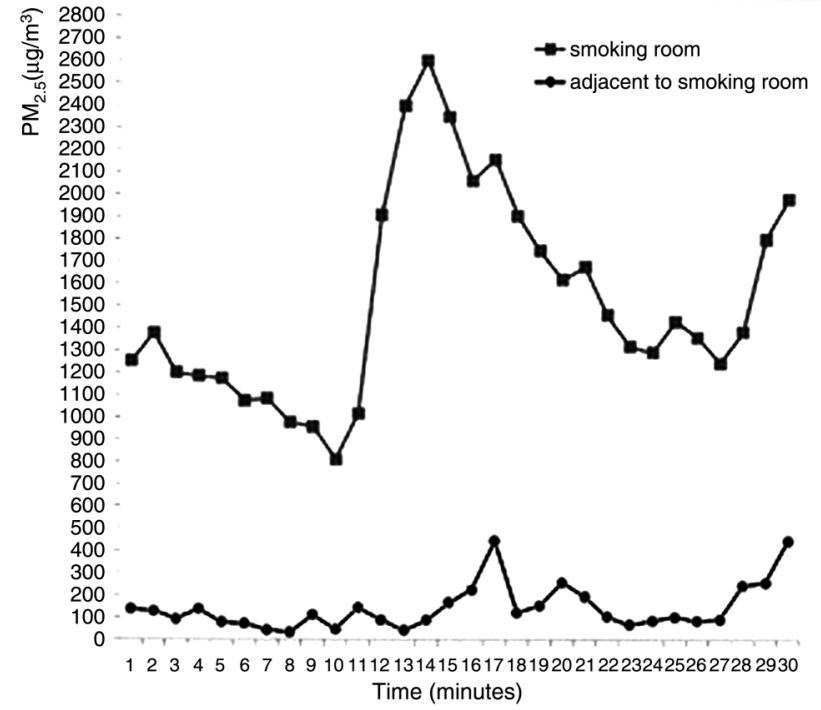

Figure 1 Real time plots of $1 \mathrm{~min}$ average values of particulate matter $\leq 2.5 \mu \mathrm{m}\left(\mathrm{PM}_{2.5}, \mu \mathrm{g} / \mathrm{m}^{3}\right)$ concentrations during a measurement session in designated smoking room (DSRs) and adjacent to DSRs in a Thai international airport.

only incremental steps towards the adoption of smoke-free areas. Complacency can develop in taking steps to remove SHS in all locations. Once partial measures are adopted, authorities may see these as adequate, compromise positions, and be unwilling to finish the job of protecting the public from SHS when no exposure is the only safe exposure. ${ }^{22}$

This study is the first undertaken in international airports in a middle-income country. The results are worse than those from the US study and do not have the limitations of lack of simultaneous monitoring and large smoking room areas that were reported as limitations in the US study. ${ }^{12}$ Yet, the limitations of this study include the naturalistic sampling and the fact that we monitored only DSRs that were active at the time of the research. However, the DSRs monitored were the most frequently used and did not differ markedly in size or design from DSRs not in use and not monitored. It is important to stress that SHS restriction is a workplace measure important to employers, employees and the public. In addition, because evaluation for occupational compliance is improving, Thailand should act now to ensure SHS levels are addressed to remove possible occupational threats and liabilities of such exposures in international airports. ${ }^{23} 24$ One implication of this study is that other countries, especially in Asia, should be aware of the possible high exposure levels in their international airports given that all large hub airports in Asia presently have smoking rooms or facilities. $^{25}$

\section{CONCLUSION}

Findings show that just as in the USA, DSRs in Thailand fail to provide a safe, healthful environment inside airports for employees and international air travellers. Although many factors during the incremental changes to smoke-free policy in Thailand may be responsible for this gap in smoke-free coverage, our findings point to the need to put health and safety concerns first in addressing SHS in Thai airports. Arguments to block or delay smoke-free airports in Thailand are simply untenable in the face of such high SHS levels, and remedial steps must be taken if these high exposure levels are to be eliminated. Past smoke-free efforts in Thailand have resulted in research bringing recognition of the dangers of SHS, legislation that now prohibits smoking in most work and public places, and a future where other places (cars, multi-unit housing and homes) will become smoke free. From the Thai perspective, an important signal of the success of this advance is to finish the job of removing DSRs in airports.

\section{What this paper adds}

- Provides specific environmental evidence about how badly airport designated smoking rooms fail in one middle-income country in comparison to recent findings from airports in the USA.

- Highlights the need for remedial action to remove the serious environmental hazards of secondhand smoke which may affect airport workers, sensitive groups and an unsuspecting population of air travellers.

Contributors All authors made a substantial contribution to this research; HC, SP, NK and NC conceptualised/planned the study; NC, NK, JP and SH performed acquisition of data; ST, NK, NC and JP analysed and interpreted the data. All authors drafted/revised the manuscript and gave final approval to the version to be published.

Funding This work was supported by the Tobacco Control Research and Knowledge Management Center, Bangkok, Thailand. Additionally, the study was partially supported for publication by the China Medical Board (CMB), Faculty of Public Health, Mahidol University, Bangkok, Thailand.

\section{Competing interests None.}

Provenance and peer review Not commissioned; externally peer reviewed.

Data sharing statement Data from this study are available to colleagues interested in comparative work on a case by case basis.

\section{REFERENCES}

1 Royal Thai Government. Non-Smokers' Health Protection Act, 1992. Bangkok: Royal Thai Government, 1992.

2 Charoenca N, Kungskulniti K, Hamann SL, et al. Exposure levels of carbon monoxide and nicotine at restaurants and nightclubs in Bangkok. Bull Health Sci Tech 2002; 5:115-24.

3 Barnoya J, Glantz SA. The tobacco industry's worldwide ETS consultants project: European and Asian components. Eur J Public Health 2006;16:69-77.

4 Dearlove J, Aguinaga Bialous S, Glantz S. Tobacco industry manipulation of the hospitality industry to maintain smoking in public places. Tob Control 2002;11:94-104.

5 Hyland A, Travers MJ, Dresler C, et al. A 32-country comparison of tobacco smoke derived particle levels in indoor public places. Tob Control 2008;17:159-65.

6 Wipfli H, Avila-Tang E, Navas-Acien A, et al. Secondhand smoke exposure among women and children: evidence from 31 countries. AJPH 2008;98:672-9.

7 Yong $\mathrm{HH}$, Foong $\mathrm{K}$, Borland $\mathrm{R}$, et al. Support for and reported compliance among smokers with smoke-free policies in air-conditioned hospitality venues in Malaysia and Thailand: findings from the International Tobacco Control Southeast Asia Survey. Asia Pac J Public Health 2010;22:98-109.

8 Pion M, Givel MS. Airport smoking rooms don't work. Tob Control 2004;13(Suppl 1):i37-40.

9 Lee $\mathrm{K}$, Hahn EJ, Robertson $\mathrm{HE}$, et al. Air quality in and around airport enclosed smoking rooms. Nicotine Tob Res 2010;12:665-8.

10 Wagner J, Sullivan DP, Faulkner D, et al. Environmental tobacco smoke leakage from smoking rooms. J Occup Environ Hyg 2004;1:110-18.

11 Winstanley M, Woodward S, Walker N. Tobacco in Australia: Facts and Issues. 2nd edn. Melbourne: Victorian Smoking and Health Program (Quit Victoria), 1995.

12 Centers for Disease Control and Prevention (CDC). Indoor air quality at nine large-hub airports with and without designated smoking areas-United States, 2012. MMWR 2012;61:948-51.

13 American Nonsmokers' Rights Foundation. 100\% Smokefree U.S. Airports. Berkeley, CA: American Nonsmokers' Rights Foundation, 2013. http://www.no-smoke.org/pdf/ 100smokefreeairports.pdf (accessed 30 Apr 2013).

14 Royal Thai Government. Nonsmokers' Health Protection Act: Notification 19. Bangkok: Royal Thai Government, 2010. 
15 Viriyachiyo V, Lim A. Tourists' attitudes towards ban on smoking in air-conditioned hotel lobbies in Thailand. Tob Control 2009;18:238-40.

16 Sureda X, Martinez-Sanchez JM, Lopez MJ, et al. Secondhand smoke levels in public building main entrances: outdoor and indoor $\mathrm{PM}_{2.5}$ assessment. Tob Control 2012;21:543-48.

17 Connolly GN, Carpenter CM, Travers MJ, et al. How smoke-free laws improve air quality: a global study of Irish pubs. Nicotine Tob Res 2009;11:600-5.

18 World Health Organization, Europe. Air Quality Guidelines: Global Update 2005. Copenhagen, Denmark: WHO, 2006.

19 Vardavas $\mathrm{Cl}$, Anagnostopoulos N, Kougias M, et al. Acute pulmonary effects of sidestream secondhand smoke at simulated car concentrations. Xenobiotica 2013:43:509-13.

20 US Department of Health and Human Services. The Health Consequences of Involuntary Exposure to Tobacco Smoke: A Report of the Surgeon General. Atlanta, GA: US Department of Health and Human Services, Centers for Disease
Control and Prevention, Coordinating Center for Health Promotion, National Center for Chronic Disease Prevention and Health Promotion, Office on Smoking and Health, 2006.

21 Glantz SA. Israel is failing to protect its citizens from secondhand smoke : underestimating public support. Israel I Health Policy Res 2013;2:24.

22 Sanders-Jackson A, Gonzalez M, Zerbe B, et al. The patterns of indoor smoking restriction laws transitions, 1970-2009: laws are sticky. Am J Public Health 2013;103:e44-51.

23 Zellers L, Thomas MA, Ashe M. Legal risks to employers who allow smoking in the workplace. Am J Public Health 2007:97:1376-82.

24 Wan X, Stillman F, Liu H, et al. Development of policy performance indicators to assess the implementation of protection from exposure to secondhand smoke in China. Tob Control 22(Suppl 2):iig-15.

25 Airports Council International. 2011 World Airport Traffic Report. Montreal: Airports Council International, 2011 